\title{
Identity Processes and Parent-Child and Sibling Relationships in Adolescence: A Five-Wave Multi-Informant Longitudinal Study
}

\author{
Elisabetta Crocetti and Susan Branje \\ Utrecht University
}

\author{
Hans M. Koot \\ VU University
}

\author{
Monica Rubini \\ University of Bologna \\ Wim Meeus
}

Utrecht University and Tilburg University

\begin{abstract}
The purpose of this study was to examine reciprocal associations between identity processes (commitment, indepth exploration, and reconsideration of commitment) and dimensions (support, negative interaction, and power) of maternal, paternal, and sibling relationships. A total of 497 Dutch families including 14-years-old adolescents (56.9\% males), their fathers, mothers, and siblings, for a total of 1,988 respondents, participated in a five-wave longitudinal study. Cross-lagged analyses indicated that commitment and in-depth exploration predicted improvements in family relationships (unidirectional effects), whereas reconsideration of commitment was predicted by low levels of maternal support and worsened the quality of the paternal relationship (reciprocal effects). These results were not moderated by adolescents' gender and sibling characteristics. Theoretical and practical implications are discussed.
\end{abstract}

Identity formation is a core developmental task of adolescence (Erikson, 1950). This task does not occur in a social vacuum; rather it is intimately related to the resources and challenges offered by the social context in which youth comes to age (Cooley, 1908). Although a considerable literature has proved that identity formation is associated with family relationships (Årseth, Kroger, Martinussen, \& Marcia, 2009; Meeus, Iedema, Maassen, \& Engels, 2005; Meeus, Oosterwegel, \& Vollebergh, 2002), the over reliance on cross-sectional evidence limits the understanding of the reciprocal dynamic process by which relationships with family members shape and are shaped by adolescents' identity. Do family relationships unidirectionally predict adolescents' identity development? Or, does

Data from the Research on Adolescent Development and Relationships (RADAR) study were used for this study. RADAR has been financially supported by main grants from the Netherlands Organization for Scientific Research (GB-MAGW 480-03-005 and GB-MAGW 480-08-006) and Stichting Achmea Slachtoffer en Samenleving (SASS), and various other grants from the Netherlands Organization for Scientific Research, the VU University Amsterdam, and the Utrecht University. Furthermore, this study was supported by grants to Wim Meeus and the Consortium Individual Development (CID, Grant 024.001.003) from the Netherlands Organization for Scientific Research (NWO).

Correspondence concerning this article should be addressed to Elisabetta Crocetti, Research Centre Adolescent Development, Utrecht University, Martinus J. Langeveldgebouw, Heidelberglaan 1, 3584CS Utrecht, The Netherlands. Electronic mail may be sent to e.crocetti@uu.nl. adolescents' identity development predict changes in family relationships? In this longitudinal study involving all family members, we addressed these research questions by testing for the first time the pattern of reciprocal associations between adolescents' identities and the quality of the relationships with their fathers, mothers, and siblings. Doing so, we could unveil whether adolescent identity formation is mainly intertwined with distancing family relationships, as hypothesized in the separation-individuation perspective (Blos, 1979), or close and supportive family relationships, as proposed by the attachment theory (Bowlby, 1988), and we could further highlight the role of intragenerational relationships with siblings.

\section{Identity Formation in Adolescence}

In Erikson's (1950) psychosocial theory of the life span, identity formation was conceptualized as the most important developmental task of adolescence. In fact, in this period adolescents can start rethinking their childhood identifications and making new choices fitting with their potentials and talents (Marcia, 1966). Doing so, they may oscillate

(C) 2016 The Authors

Child Development (c) 2016 Society for Research in Child Development, Inc. All rights reserved. 0009-3920/2017/8801-0017

DOI: $10.1111 /$ cdev.12547 
between two poles (Erikson, 1968), moving toward identity synthesis (making meaningful choices about their personal identity) or regressing to identity confusion (lacking important commitments that could provide them with a sense of direction and purpose).

In this study, we adopted a three-factor process model aimed at capturing the dynamic process by which identity is formed and revised over time (Crocetti, Rubini, \& Meeus, 2008; for a review, see Meeus, 2011). In this model, three pivotal identity processes are taken into account to parsimoniously explain identity dynamics. Commitment refers to enduring choices that individuals have made with regard to various developmental domains and to the self-confidence they derive from these choices. In-depth exploration represents the extent to which individuals think actively about the commitments they have enacted (e.g., reflecting on their choices, searching for additional information, talking with others about their commitments). Reconsideration of commitment refers to the comparison of present commitments with possible alternative commitments because the current ones are no longer satisfactory.

In this model, it is assumed that individuals enter adolescence with a set of commitments that are of at least minimal strength in important ideological and interpersonal identity domains (Meeus, van de Schoot, Keijsers, Schwartz, \& Branje, 2010). Thus, individuals approach adolescence evaluating and questioning their preliminary commitments, based on childhood identifications. In fact, the three-factor model includes a dual-cycle process (Luyckx, Goossens, \& Soenens, 2006; Meeus, 2011) based on the interplay of the identity-maintenance and identity-revision cycles. Specifically, by exploring their present commitments, adolescents invest in maintaining them and make sure that they provide a good fit with their overall talents and potentials (identity-maintenance cycle). If one's current commitments are not satisfying or do not provide a good fit, they may be reconsidered in favor of new ones (the identity-revision cycle).

Thus, by including commitment, in-depth exploration, and reconsideration of commitment, this model sought to capture Erikson's (1968) dynamic of identity synthesis versus role confusion. Commitment and in-depth exploration, on the one hand, and reconsideration, on the other hand, are conceptualized as two opposing forces within this dynamic (Meeus et al., 2010). Although commitment and in-depth exploration imply attempts to develop and maintain a sense of self (i.e., identity coherence or synthesis), reconsideration represents questioning and rethinking this sense of self (identity confusion).

Longitudinal studies monitoring the three identity processes over the course of adolescence pointed out slight progressive identity changes (see Meeus, 2011, for a review). This maturation was expressed by increasing levels of commitment and in-depth exploration and decreasing levels of reconsideration of commitment. Various individual factors have been found to account for differences in identity formation over the course of adolescence (e.g., personality, Luyckx, Soenens, \& Goossens, 2006; early history of problem behaviors, Crocetti, Klimstra, Hale, Koot, \& Meeus, 2013; Crocetti, Klimstra, Keijsers, Hale, \& Meeus, 2009). In contrast, the dynamic process by which adolescents develop their identity in interaction with the social context is less understood (Bosma \& Kunnen, 2008). For this reason, in this study we sought to examine the reciprocal associations between family relationships and adolescent identity development.

\section{Family Relationships and Adolescent Identity}

Many of the social interactions that may guide the developing adolescent's identity take place in the family context. In particular, the family represents the first microsystem in which individual development occurs (Bronfenbrenner, 1979). Thus, to understand identity formation it is necessary to take into account how it develops within the family system (Schachter \& Ventura, 2008). In this respect, it is worth emphasizing that the family is a comprehensive system, in which intergenerational (parentchild relationships) and intragenerational (sibling relationships) interactions occur at the same time (Scabini, Marta, \& Lanz, 2006). These interactions are interdependent, with the quality of maternal, paternal, and sibling relationships being all interrelated (Branje, Van Aken, \& Van Lieshout, 2002; Kenny, Kashy, \& Cook, 2006). Up to now, the literature has focused mainly on the associations between parent-child relationships and adolescent identity, whereas the role of siblings has received limited attention.

\section{Parent-Child Relationships and Identity}

From a theoretical point of view, parent-child relationships can both foster adolescent identity formation and be modeled by processes of identity formation. So far, the family literature has been mainly focused in explaining how family 
relationships can promote identity formation. In this respect, family is not considered as a "neutral environment. In contrast, it deeply affects the individual process, starting during adolescence, that leads to the development of one's identity" (Scabini \& Manzi, 2011, p. 573).

Several theories of parent-adolescent relationships share the notion that parents affect children's identity formation but differ in their explanatory models. For instance, the separation-individuation theory (Blos, 1979) outlines that separation from parents is a precursor of identity formation. In contrast, most current researchers adopt the theoretical framework provided by attachment theory (Bowlby, 1988), which views a secure bond with parents as necessary for exploring identity with confidence and making independent choices and decisions while being able to count on parents for support. So, these theories present different conceptualizations on the link between family relationships and identity formation.

In contrast, the analysis of how adolescent identity can influence family relationships has received less attention. However, building upon Erikson's (1950) psychosocial theory, it can be argued that, similarly to family relationship influencing identity formation, identity formation also might influence family relationships. Erikson (1968, p. 167) wrote that the "true engagement with others is the result and the test of firm self-definition." This suggests that when adolescents achieve higher identity maturity they are likely to improve their interactions with significant others, for instance by establishing more equal and mutual relationships. This is consistent with Erikson's assumption that the optimal resolution of the identity formation task is a precursor of intimate and caring (generative) interpersonal relationships (Beyers \& Seiffge-Krenke, 2010). Furthermore, the cluster of problems (e.g., anxiety, depression, rule breaking, aggressive behaviors, emotional instability, and avoidant cognitive strategies; Crocetti et al., 2013; Crocetti, Klimstra, et al., 2009; Crocetti, Rubini, Berzonsky, \& Meeus, 2009) that is associated with adolescent identity insecurity can interfere with interpersonal relationships, making interactions with parents more difficult. Thus, from a theoretical point of view, it is possible to hypothesize that adolescent identity can also influence family relationships.

The theoretical models reviewed so far point to reciprocal associations between identity and family relationships. To what extent has empirical evidence supported this view? Most of the empirical studies on identity and family relationships have used a cross-sectional design. Available evidence highlights that identity is positively associated with warm and nurturing parent-child relationships (Årseth et al., 2009). For instance, identity commitment and in-depth exploration have been found to be positively related to paternal and maternal trust, whereas reconsideration of commitment was negatively linked to them (Crocetti, Schwartz, Fermani, \& Meeus, 2010; Morsunbul, Crocetti, Cok, \& Meeus, 2014) and was positively related to psychological control (Crocetti et al., 2008). However, this cross-sectional evidence prevents us from drawing conclusions about developmental directions.

To further understand whether family relationships predict identity formation and/or identity explains changes in family relationships, it is necessary to consider fully recursive longitudinal designs, in which both parent-adolescent relationships and adolescent identity processes are measured at multiple waves. Available longitudinal studies have mainly addressed this interplay of family relationships and identity in emerging adult samples, consisting of college students (Beyers \& Goossens, 2008; Kroger \& Haslett, 1988; Luyckx, Soenens, Vansteenkiste, Goossens, \& Berzonsky, 2007). These studies pointed out reciprocal associations between various indicators of the quality of family relationships and identity processes of commitment and exploration. For instance, Beyers and Goossens (2008) found that higher initial levels of maternal supportive parenting led to decreases in exploration in breadth of various identity alternatives, while higher initial levels of commitment and in-depth exploration (the processes at the basis of the identity-maintenance cycle) led to increasing levels of maternal and paternal supportive parenting. Similarly, Luyckx et al. (2007) found that the more college students perceived their parents as psychologically controlling, the more difficulties they experienced in committing to meaningful life domains; and the more they explored in breadth various identity alternatives, the more their parents were perceived as increasing in their intrusive psychological control. Taken together, these results suggest bidirectional linkages between family relationships and identity. However, this evidence derives from emerging adult samples (college students), and we do not know to what extent this pattern of associations applies also to adolescents. In fact, the transition from adolescence to emerging adulthood is generally characterized by an improvement in parent-child relationships (e.g., Crocetti \& Meeus, 2014) that might reinforce the 
interplay of family bonds and identity. Furthermore, the studies reviewed above were all based on youth self-reports (i.e., participants evaluated both their identity and their family relationships), and thus, they can be subjected to reporter biases (Luyckx et al., 2007).

Preliminary evidence suggests that the interplay between family relationships and identity might become bidirectional over the course of adolescence. Specifically, Schwartz, Mason, Pantin, and Szapocznik (2009) studied the linkages between family functioning and Eriksonian indicators of identity confusion in 12-16 years old Hispanic adolescents. Participants were involved in an HIV prevention study with their primary caregivers (mainly mothers). The authors found that the link between family functioning and identity becomes increasingly bidirectional during adolescence.

It has been also suggested that paternal and maternal impacts on identity formation might differ. A set of cross-sectional studies with college students provided some evidence in this direction. For instance, Benson, Harris, and Rogers (1992) found that attachment to mothers was positively related to adolescent identity achievement, and it was negatively related to identity moratorium and diffusion; whereas attachment to father was positively related to identity foreclosure. Fullinwider-Bush and Jacobvitz (1993) found that young women's exploration was positively related to parents' autonomy support, but it was negatively related to parent-child boundary dissolution, characterized by role reversal, enmeshment, and overinvolvement. In addition, Fullinwider-Bush and Jacobvitz reported that poor autonomy support from both mothers and fathers was linked to young women' low exploration, but only low autonomy support by fathers was related to low identity commitments. In contrast, other studies did not find differences in maternal and paternal effects. For instance, Samuolis, Layburn, and Schiaffino (2001) found that attachment to both mothers and fathers was positively correlated with commitment but only for girls, whereas attachment to mothers and fathers was unrelated to exploration for both boys and girls. In their longitudinal study with college students, Beyers and Goossens (2008) demonstrated that higher initial levels of commitment and indepth exploration led to increasing levels of both maternal and paternal supportive parenting. Taken together, the above studies highlight some potential differences between fathers and mothers, but findings are inconsistent. Furthermore, all these studies involved college students. Thus, it is important to further clarify to what extent associations between parent-child relationships and adolescent identity differ for fathers and mothers.

In light of these considerations, in this study we sought to further disentangle associations between relationships with fathers and mothers and identity in adolescence by means of a multiinformant design. We tested reciprocal effects, hypothesizing that relationships with parents would influence adolescent identity formation and adolescent identity would affect quality of family relationships. In addressing the first effect (the one of family on identity) we could also test for different theories, examining whether adolescent identity is triggered by parents' separation (in accordance with separation-individuation perspective; Blos, 1979) or by parents' connectedness and closeness (consistent with the attachment theory; Bowlby, 1988).

\section{Sibling Relationships and Identity}

Within the family system both intergenerational relationships with parents and intragenerational relationships with siblings can affect and be affected by adolescents' developing identities. However, the literature on family relationships and identity has been almost completely focused on parentadolescent relationships, leaving the role of sibling relationships largely unexplored. Thus, in this study we sought to provide a novel contribution examining how adolescent identity is associated also with sibling relationships.

Sibling relationships undergo significant changes during adolescence. Similarly to changes in parentchild relationships (e.g., De Goede, Branje, \& Meeus, 2009), sibling relationships also become less intense, more egalitarian, and less asymmetrical with age (Buhrmester \& Furman, 1990). Despite these changes, the relationship with siblings continues to be very important for adolescents, and it is related to their development (Branje, Van Lieshout, Van Aken, \& Haselager, 2004; Brody, 1998; Defoe et al., 2013; McHale, Updegraff, \& Whiteman, 2012; Patterson, 1984). In their meta-analytic review, Buist, Deković, and Prinzie (2013) found that quality of sibling relationships was significantly related to internalizing and externalizing problem behaviors, with warmth being a protective factor and conflict a risk factor. Overall, this evidence suggests that quality of sibling relationships is related to adolescent psychosocial development.

Notwithstanding the demonstrated importance of siblings for adolescent development, to the best 
of our knowledge, so far only two longitudinal studies (Watzlawik \& Clodius, 2011; Wong, Branje, VanderValk, Hawk, \& Meeus, 2010) have paid attention to the role of siblings in identity formation. Specifically, Watzlawik and Clodius (2011) found a general decrease in the extent to which adolescents feel committed to and derive self-confidence, a positive self-image, and optimism in the future from their siblings' relationships. Wong et al. (2010) investigated the interplay of adolescents' and their siblings' levels of identity commitment and exploration. They found evidence for sibling identification processes, but limited to in-depth exploration, because levels of commitment of adolescents and their siblings were mainly unrelated. Although this evidence sheds new light on the role of siblings for adolescents' identity formation, it leaves a main question still unanswered: Is the quality of sibling relationships bidirectionally related to adolescent identity formation?

Theoretically, the association between quality of sibling relationships and adolescent identity formation can be conceptualized as a reciprocal one. Drawing from the social learning theory (Bandura, 1977), we can expect that bidirectional processes of modeling occur in the interaction with siblings. More specifically, adolescents who have positive relationships with their siblings are more likely to interact with one another, thus experiencing more opportunities to observe and learn from each other (Brody, 1998). Furthermore, siblings who share values and interests may increase their interpersonal contact and experience growing positivity in their interactions (Brody, 1998).

This modeling effect can also depend on sibling characteristics, such as sibling age and sibling gender similarity (McHale et al., 2012). In particular, older siblings inherit positions of authority and responsibility toward younger siblings. Thus, older siblings may have a stronger modeling effect on younger children than the other way around. Although it should be noted that these differences in power and status occur mainly in childhood and tend to disappear during adolescence, when the sibling relationships become less asymmetrical (Buhrmester \& Furman, 1990). Furthermore, variations in the gender composition of the sibling dyads account for a modest amount of the variance in sibling relationships with same-sex siblings feeling closer than opposite-sex siblings (Buhrmester \& Furman, 1990; Buist, Deković, Meeus, \& Van Aken, 2002). Thus, it could be that modeling effects can be slightly stronger in same-sex than in opposite-sex sibling dyads.

\section{The Present Study}

Consistent with the current state of the literature on family relationships and identity, the purpose of the present study was to unfold bidirectional associations between the quality of family ties and adolescents' identity processes. In order to advance our understanding of this phenomenon, we employed a fully recursive five-wave longitudinal design involving all family members (the target adolescents, their mothers, fathers, and siblings). Doing so, we could (a) examine bidirectional associations between quality of relationships and identity, and (b) conduct a more rigorous test of these associations, with the quality of the relationships not selfreported by the adolescents but evaluated directly by their family members.

In order to gain a comprehensive understanding of the interplay of family relationships and identity, we disentangled reciprocal associations between the three identity processes of commitment, in-depth exploration, and reconsideration of commitment (Crocetti et al., 2008) and multiple indicators of quality of family relationships. Specifically, we operationalized quality of family relationships considering levels of maternal, paternal, and sibling support; negative interactions (the intensity of conflict and antagonism, representing an indicator of interpersonal distance); and power (De Goede et al., 2009; Furman \& Buhrmester, 1985). These dimensions tap into different aspects of family relationships, and their assessment can help clarifying whether identity formation is intertwined with close and supportive (for instance, as emphasized in the attachment theory; Bowlby, 1988) or distancing (as underlined in the separation-individuation perspective; Blos, 1979) family relationships.

Consistent with the theoretical background (Bowlby, 1988; Erikson, 1950; Erikson, 1968; Grotevant \& Cooper, 1985; Grotevant \& Cooper, 1986) and prior empirical evidence (Beyers \& Goossens, 2008; Luyckx et al., 2007; Meeus et al., 2005), we hypothesized bidirectional developmental patterns. In fact, we expected that (a) high-quality relationships (indicated by high levels of support, low negative interactions, and low power) would foster adolescents' identity formation, and (b) adolescents' enactment of a more mature identity (expressed by increasing levels of commitment and in-depth exploration, and decreasing levels of reconsideration of commitment) would improve the quality of family relationships. We further expected that these patterns of interactions would apply to both intergenerational (parent-adolescent 
relationships) and intragenerational (sibling relationships) bonds.

Finally, we examined whether the pattern of associations between identity and family relationships was moderated by adolescents' gender and by sibling characteristics. With respect to adolescents' gender, some authors (e.g., Grotevant \& Cooper, 1985) have suggested that the source of family influences on identity may be different for female and male adolescents, whereas other authors (e.g., Luyckx et al., 2007) have hypothesized that the pattern of associations between family relationships and identity would hold across gender groups. Sibling characteristics (e.g., McHale et al., 2012) that might influence associations between family relationships and identity are sibling gender (from which is possible to differentiate between same-sex and opposite-sex sibling dyads) and sibling age (with younger vs. older siblings). Therefore, we tested whether the longitudinal associations between various dimensions of fathers, mothers, and siblings' relationships and identity processes were similar for boys and girls, for adolescents with same-sex versus opposite-sex siblings, and for those with younger versus older siblings.

\section{Method \\ Participants}

Data for this study were drawn from the ongoing longitudinal RADAR-young project (Research on Adolescent Development and Relationships [RADAR]-younger cohort), a population-based prospective cohort study conducted in the Netherlands. The RADAR-young project started when adolescents were 13 years old. Data were collected from 2005 until 2011. However, identity measures were added in the second wave of data collection, conducted when adolescents were 14 years old. Thus, participants in the current study were 497 Dutch families including the target adolescents $\left(56.9 \%\right.$ males; baseline $\left.M_{\text {age }}=14.03, S D_{\text {age }}=0.46\right)$, their fathers (baseline $M_{\text {age }}=47.68, S D_{\text {age }}=5.10$ ), mothers (baseline $M_{\text {age }}=45.40, S D_{\text {age }}=4.45$ ), and siblings $\left(44.8 \%\right.$ males; baseline $M_{\text {age }}=15.73$, $\left.S D_{\text {age }}=3.14\right)$, for a total of 1,988 respondents. More specifically, all participating adolescents were attending secondary schools. Most adolescents were native Dutch (95\%), lived with both parents $(86 \%)$, and came from families classified as medium or high socioeconomic status $(89 \%)$. The majority of adolescents $(70 \%)$ had an older sibling (baseline $M_{\text {age }}=17.42, S D_{\text {age }}=2.05$, age range $=13.75 / 24.41 ;$
$41.1 \%$ males), while $30 \%$ of adolescents had a younger sibling (baseline $M_{\text {age }}=11.81, S D_{\text {age }}=$ 1.03 , age range $=8.16 / 14.16 ; 54 \%$ males). Furthermore, $52.3 \%$ of target adolescents and their siblings had the same gender.

For the current study, each member of the family unit provided information for five waves, with a 1year interval between each pair of waves. Thus, adolescents were 14 years old during the 1st year of assessment and they were followed until they were 18 years old. Of the original sample, 425 families $(86 \%)$ were still involved in the study at the last wave, and the average participation rate over the five waves was 90\%. Results of Little's (1988) Missing Completely at Random test yielded normed $\chi^{2} \mathrm{~s}$ $\left(\chi^{2} / d f\right)$ of $1.03,1.08,1.14$, and 1.08, for adolescents, fathers, mothers, and siblings' data, respectively. Therefore, all the 497 families were included in the analyses conducted by means of the full information maximum likelihood procedure available in Mplus.

\section{Procedure}

The RADAR study has been approved by the Medical Ethical Committee of Utrecht University Medical Centre (the Netherlands). Before the start of the study, adolescents and their parents received written information about the study and they were all asked to provide their informed consent. Within each year of the study, trained research assistants made appointments for annual home visits. During these visits, participants completed a battery of questionnaires. Research assistants provided verbal instructions in addition to the written instructions that accompanied the questionnaires.

\section{Measures}

\section{Identity}

Data on identity processes were provided by the adolescents, who completed the Dutch version of the Utrecht-Management of Identity Commitments Scale (U-MICS; Crocetti et al., 2008). The U-MICS consists of 26 items with a response scale ranging from 1 (completely untrue) to 5 (completely true). Thirteen items index the target processes in one ideological domain (education), and 13 items index the target processes in one interpersonal domain (friendship). Sample items include: "My education/ best friend gives me certainty in life" (commitment, 10 items), "I think a lot about my education/best friend" (in-depth exploration, 10 items), and "I often think it would be better to try to find a 
different education/best friend" (reconsideration of commitment, 6 items). Although the U-MICS assesses identity in different domains, the instrument can be employed to measure overall identity, summing responses across the two domains. Confirmatory factor analyses demonstrated the internal validity of the three-dimensional model across domains in different gender, age, ethnic, and cultural groups (Crocetti et al., 2008, 2010, 2015; Morsunbul et al., 2014). In this study, Cronbach's alphas of the U-MICS subscales ranged across waves from .89 to .91 for commitment, from .84 to .85 for in-depth exploration, and from .80 to .84 for reconsideration of commitment, respectively.

\section{Family Relationships}

Data on relationships were provided directly by participating fathers, mothers, and siblings who evaluated their relationships with the target adolescents by completing the short version of the Network of Relationships Inventory (NRI; Furman \& Buhrmester, 1985, 1992; for information about the validity of the Dutch version, see De Goede et al., 2009). Each family member completed the NRI items using a response scale from 1 (a little or not at all) to 5 (more is not possible). Sample items include: "How much do you really care about your child/sibling?" (support, eight items), "Do you and your child/sibling get on each other's nerves?" (negative interaction, six items), and "To what extent is your child/sibling the boss in your relationship?" (power, six items). In the current study, Cronbach's alphas ranged across waves from .75 to .81 for father, from .70 to .78 for mother, and from .81 to .85 for sibling support; from .90 to .92 for father, from .90 to .92 for mother, and from .94 to .96 for sibling negative interaction; and from .78 to .83 for father, from .77 to .83 for mother, and from .90 to .93 for sibling power, respectively.

\section{Results \\ Preliminary Analyses}

Means and standard deviations of the study variables are reported in Table 1. Correlations among study variables are displayed in Table 2.

\section{Cross-Lagged Analyses}

The purpose of this study was to examine reciprocal associations between identity and family relationships over the course of adolescence. In order to reach this aim we conducted cross-lagged analyses in Mplus 7.3 (Muthén \& Muthén, 1998-2012), using the maximum likelihood robust estimator (Satorra \& Bentler, 2001). As a preliminary step, we tested longitudinal measurement invariance. Thus, for each construct we compared the configural (baseline) model with the metric model, in which factor loadings were constrained to be equal across

Table 1

Means and Standard Deviations (in Parentheses) of Study Variables

\begin{tabular}{|c|c|c|c|c|c|}
\hline & $\mathrm{T} 1$ & $\mathrm{~T} 2$ & T3 & $\mathrm{T} 4$ & T5 \\
\hline \multicolumn{6}{|l|}{ Fathers' relationship } \\
\hline Support & $3.22(0.47)$ & $3.24(0.47)$ & $3.20(0.48)$ & $3.19(0.48)$ & $3.19(0.52)$ \\
\hline Negative interaction & $1.52(0.53)$ & $1.51(0.52)$ & $1.53(0.51)$ & $1.51(0.53)$ & $1.47(0.49)$ \\
\hline Power & $1.66(0.42)$ & $1.67(0.42)$ & $1.68(0.43)$ & $1.70(0.45)$ & $1.72(0.48)$ \\
\hline \multicolumn{6}{|l|}{ Mothers' relationship } \\
\hline Support & $3.44(0.44)$ & $3.44(0.44)$ & $3.44(0.45)$ & $3.41(0.47)$ & $3.44(0.50)$ \\
\hline Negative interaction & $1.55(0.54)$ & $1.52(0.50)$ & $1.55(0.56)$ & $1.50(0.54)$ & $1.48(0.54)$ \\
\hline Power & $1.52(0.39)$ & $1.54(0.39)$ & $1.57(0.45)$ & $1.58(0.42)$ & $1.59(0.45)$ \\
\hline \multicolumn{6}{|l|}{ Siblings' relationship } \\
\hline Support & $3.13(0.68)$ & $3.21(0.65)$ & $3.24(0.63)$ & $3.25(0.65)$ & $3.33(0.67)$ \\
\hline Negative interaction & $2.36(0.81)$ & $2.22(0.81)$ & $2.13(0.82)$ & $1.95(0.79)$ & $1.86(0.73)$ \\
\hline Power & $1.81(0.69)$ & $1.80(0.72)$ & $1.81(0.69)$ & $1.79(0.66)$ & $1.82(0.71)$ \\
\hline \multicolumn{6}{|l|}{ Adolescents' identity } \\
\hline Commitment & $3.66(0.63)$ & $3.62(0.66)$ & $3.60(0.66)$ & $3.64(0.69)$ & $3.57(0.72)$ \\
\hline In-depth exploration & $3.24(0.64)$ & $3.25(0.64)$ & $3.18(0.66)$ & $3.25(0.66)$ & $3.21(0.65)$ \\
\hline Reconsideration of commitment & $1.87(0.76)$ & $1.84(0.73)$ & $1.89(0.76)$ & $1.88(0.77)$ & $2.01(0.81)$ \\
\hline
\end{tabular}

Note. $\mathrm{T}=$ time 
Table 2

Within-Time Bivariate Correlations Between Identity Processes and Family Relationships

$\begin{array}{ccc}\text { Commitment } & \text { In-depth exploration } & \text { Reconsideration of commitment } \\ \mathrm{T} 1 / \mathrm{T} 2 / \mathrm{T} 3 / \mathrm{T} 4 / \mathrm{T} 5 & \mathrm{~T} 1 / \mathrm{T} 2 / \mathrm{T} 3 / \mathrm{T} 4 / \mathrm{T} 5 & \mathrm{~T} 1 / \mathrm{T} 2 / \mathrm{T} 3 / \mathrm{T} 4 / \mathrm{T} 5\end{array}$

\begin{tabular}{|c|c|c|c|}
\hline \multicolumn{4}{|l|}{ Fathers } \\
\hline Support & $.09 / .11^{*} / .14^{* *} / .03 / .10$ & $.06 / .04 / .01 / .02 / .00$ & $-.11^{*} /-.08 /-.14^{* *} /-.14^{* *} /-.21^{* * *}$ \\
\hline Negative & $-.13^{* *} /-.15^{* *} /-.12^{*} /-.07 /-.08$ & $-.02 /-.06 / .01 / .02 / .02$ & $.10^{*} / .09 / .15^{* *} / .10 / .02$ \\
\hline Power & $-.01 /-.07 /-.05 /-.00 / .02$ & $.02 /-.04 /-.13^{* *} /-.03 /-.03$ & $-.08 /-.08 / .01 /-.07 /-.15^{* *}$ \\
\hline \multicolumn{4}{|l|}{ Mothers } \\
\hline Support & $.06 / .11^{*} / .06 / .09 / .15^{* *}$ & $.04 / .10^{*} /-.02 / .07 / .13^{* *}$ & $-.11^{*} /-.11^{*} /-.13^{* *} /-.11^{*} /-.24^{* * *}$ \\
\hline Negative & $-.19^{* * *} /-.13^{* *} /-.07 /-.16^{* * *} /-.16^{* * *}$ & $-.05 / .00 /-.01 /-.02 /-.04$ & $.09 / .11^{*} / .15^{* *} / .12^{*} / .11^{*}$ \\
\hline Power & $-.05 /-.03 /-.03 /-.08 /-.04$ & $-.02 / .03 / .04 /-.04 /-.07$ & $.01 / .02 / .14^{* *} / .12 * /-.04$ \\
\hline \multicolumn{4}{|l|}{ Siblings } \\
\hline Support & $.11^{*} / .05 / .13^{* *} / .07 / .02$ & $.09 / .04 / .03 /-.02 / .07$ & $-.12^{*} /-.16^{* *} /-.04 /-.02 /-.02$ \\
\hline Negative & $-.04 /-.05 /-.10 * /-.02 / .02$ & $-.07 /-.07 /-.07 / .01 / .02$ & $.05 / .09 / .14^{* *} /-.02 / .04$ \\
\hline Power & $.08 / .00 /-.00 /-.01 /-.10$ & $-.00 /-.01 /-.02 / .01 /-.01$ & $-.05 /-.05 / .01 /-.02 / .06$ \\
\hline
\end{tabular}

Note. $\mathrm{T}=$ time; negative $=$ negative interaction. ${ }^{*} p<.05 .{ }^{* *} p<.01 .{ }^{* * *} p<.001$.

time. Model comparisons were conducted considering changes in fit indices (e.g., Chen, 2007). Findings indicated the establishment of metric invariance for all study constructs.

We then tested three cross-lagged models, one for each identity process. In each model, we tested (a) cross-lagged paths from family dimensions to identity (e.g., maternal support predicting commitment) and from identity to family dimensions (e.g., commitment predicting maternal support) controlling for (b) 1-year (e.g., commitment at T1 predicting commitment at T2) and 2-year (e.g., commitment at T1 predicting commitment at T3) stability paths; and (c) within-time correlations among all variables. A schematization of the tested model is reported in Figure 1. We evaluated the fit of each model considering the Tucker-Lewis index (TLI) and the comparative fit index (CFI), with values higher than 0.90 indicative of an acceptable fit and values higher than 0.95 suggesting an excellent fit; and the root mean square error of approximation (RMSEA), with values below 0.08 indicative of an acceptable fit and values $<0.05$ representing a very good fit (Byrne, 2012).

To model the longitudinal associations among family dimensions and identity as parsimoniously as possible, we tested whether cross-lagged effects and T2-T5 within-time correlations (correlated changes) were time invariant. Thus, we compared the baseline unconstrained models (M1s) with the models assuming time invariance of cross-lagged associations (M2s) and of T2-T5 within-time correlations (M3s). In order to determine significant differences between models, at least two of these three criteria had to be matched: $\Delta \chi_{S B}^{2}$ significant at $p<.05$ (Satorra \& Bentler, 2001), $\Delta$ CFI $\geq-0.010$, and $\triangle R M S E A \geq 0.015$ (Chen, 2007). Findings (see Table 3) clearly supported the assumption of time invariance for each model. Thus, we could retain the most parsimonious models (M4s) with

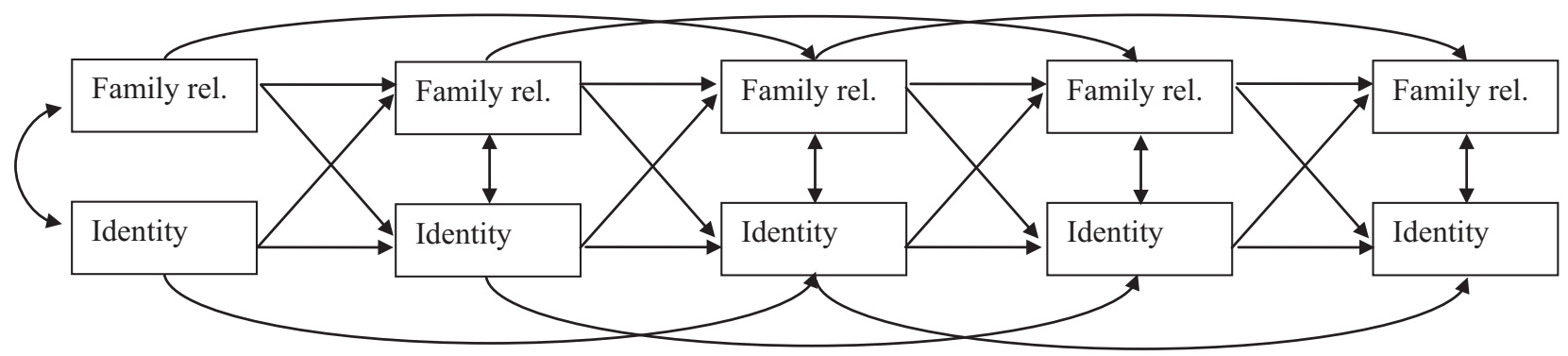

Figure 1. Schematization of the tested model. $\mathrm{T}=$ time; family rel. = family relationships. 
Table 3

Cross-Lagged Models: Fit Indices and Model Comparisons

\begin{tabular}{|c|c|c|c|c|c|c|c|c|c|c|c|}
\hline \multirow[b]{2}{*}{ Models } & \multicolumn{5}{|c|}{ Model fit indices } & \multicolumn{6}{|c|}{ Model comparison } \\
\hline & $\chi_{\mathrm{SB}}^{2}$ & $d f$ & TLI & CFI & RMSEA [90\% CI] & Models & $\Delta \chi_{\mathrm{SB}}^{2}$ & $\Delta d f$ & $p$ & $\Delta \mathrm{CFI}$ & $\triangle$ RMSEA \\
\hline \multicolumn{12}{|l|}{ Commitment } \\
\hline M1: Baseline model & $1,318.850$ & 858 & 0.943 & 0.958 & $0.033[0.030,0.037]$ & & & & & & \\
\hline $\begin{array}{l}\text { M2: Model with cross- } \\
\text { lagged paths fixed to } \\
\text { be time invariant }\end{array}$ & $1,390.074$ & 912 & 0.944 & 0.957 & $0.033[0.029,0.036]$ & M2-M1 & 70.800 & 54 & 0.062 & -0.001 & 0.000 \\
\hline $\begin{array}{l}\text { M3: Model with T2-T5 } \\
\text { within-time correlations } \\
\text { fixed to be time } \\
\text { invariant }\end{array}$ & $1,446.695$ & 993 & 0.951 & 0.959 & $0.031[0.027,0.034]$ & M3-M1 & 145.499 & 135 & 0.254 & 0.001 & -0.002 \\
\hline $\begin{array}{l}\text { M4: Final model with } \\
\text { paths and T2-T5 } \\
\text { correlations fixed to be } \\
\text { time invariant }\end{array}$ & $1,514.752$ & 1047 & 0.952 & 0.958 & $0.030[0.027,0.034]$ & M4-M1 & 210.871 & 189 & 0.132 & 0.000 & -0.003 \\
\hline \multicolumn{12}{|l|}{ In-depth exploration } \\
\hline M1: Baseline model & $1,323.470$ & 858 & 0.942 & 0.958 & $0.033[0.030,0.037]$ & & & & & & \\
\hline $\begin{array}{l}\text { M2: Model with cross- } \\
\text { lagged paths fixed to } \\
\text { be time invariant }\end{array}$ & $1,367.415$ & 912 & 0.946 & 0.959 & $0.032[0.028,0.035]$ & M2-M1 & 43.523 & 54 & 0.845 & 0.001 & -0.001 \\
\hline $\begin{array}{l}\text { M3: Model with T2-T5 } \\
\text { within-time correlations } \\
\text { fixed to be time } \\
\text { invariant }\end{array}$ & $1,464.460$ & 993 & 0.949 & 0.957 & $0.031[0.028,0.035]$ & M3-M1 & 146.314 & 135 & 0.239 & -0.001 & -0.002 \\
\hline $\begin{array}{l}\text { M4: Final model with } \\
\text { paths and T2-T5 } \\
\text { correlations fixed to be } \\
\text { time invariant }\end{array}$ & $1,506.552$ & 1047 & 0.953 & 0.958 & $0.030[0.027,0.033]$ & M4-M1 & 200.005 & 189 & 0.278 & 0.000 & -0.003 \\
\hline \multicolumn{12}{|c|}{ Reconsideration of commitment } \\
\hline M1: Baseline model & $1,289.062$ & 858 & 0.945 & 0.960 & $0.032[0.028,0.036]$ & & & & & & \\
\hline $\begin{array}{l}\text { M2: Model with cross- } \\
\text { lagged paths fixed to } \\
\text { be time invariant }\end{array}$ & 1335.160 & 912 & 0.949 & 0.961 & $0.031[0.027,0.034]$ & M2-M1 & 46.718 & 54 & 0.749 & 0.001 & -0.001 \\
\hline $\begin{array}{l}\text { M3: Model with T2-T5 } \\
\text { within-time correlations } \\
\text { fixed to be time } \\
\text { invariant }\end{array}$ & $1,438.336$ & 993 & 0.951 & 0.959 & $0.030[0.027,0.034]$ & M3-M1 & 153.461 & 135 & 0.132 & -0.001 & -0.002 \\
\hline $\begin{array}{l}\text { M4: Final model with } \\
\text { paths and T2-T5 } \\
\text { correlations fixed to be } \\
\text { time invariant }\end{array}$ & $1,485.639$ & 1047 & 0.954 & 0.959 & $0.029[0.026,0.033]$ & M4-M1 & 213.781 & 189 & 0.104 & -0.001 & -0.003 \\
\hline
\end{tabular}

Note. $\Delta \chi_{\mathrm{SB}}^{2}$ model comparisons are based on Satorra and Bentler's (2001) scaled difference chi-square test statistic. TLI $=$ Tucker-Lewis index; $\mathrm{CFI}=$ comparative fit index; RMSEA = root mean square error of approximation; $90 \% \mathrm{CI}=90 \%$ confidence interval; $\Delta=$ change in parameter.

time-invariant cross-lagged paths and $\mathrm{T} 2-\mathrm{T} 5$ within-time correlations as the final models (ancillary analyses are reported in Appendix S1). These models fit the data very well.

Finally, for each model we conducted multigroup analyses to test for the moderating effects of adolescent gender (boys vs. girls), sibling gender (same-sex vs. opposite-sex sibling dyads), and sibling age (younger vs. older siblings). Thus, we conducted for each moderating variable multigroup analyses in which we compared unconstrained models MM1s (multigroup Model 1), with constrained models MM2s (in which cross-lagged lagged paths were fixed across groups), MM3s (with T1 correlations constrained equal across groups), and MM4s (with T2-T5 correlations 
constrained equal across groups). Results of model comparisons indicated that these models did not differ from the baseline models, indicating the lack of significant moderating effects (detailed results are reported in Appendix S2). Therefore, we focused on results obtained in the total sample. Cross-lagged paths and within-time correlations between identity and family dimensions are displayed in Figures 2-4, stability paths are reported in Table 4, and correlations among family dimensions are reported in Table 5.

\section{Family Relationships and Identity Commitment}

As can be seen in Figure 2, cross-lagged effects highlighted that commitment influenced the quality of family relationships, while the inverse effect was not significant. Specifically, commitment increased later levels of maternal support and lessened maternal negative interaction and sibling power. Furthermore, at T1, commitment was negatively related to paternal and maternal negative interaction and it was positively associated with sibling support. Moreover, at T2-T5, commitment was negatively related to maternal negative interaction.

\section{Family Relationships and Identity In-Depth Exploration}

As indicated by cross-lagged paths displayed in Figure 3, as for commitment, also for in-depth exploration, the direction of effects was from identity to family relationships and not the other way around. In particular, in-depth exploration predicted improvements in the quality of family relationships, increasing levels of maternal, paternal, and sibling support, making the interaction with
$\mathrm{T} 1$

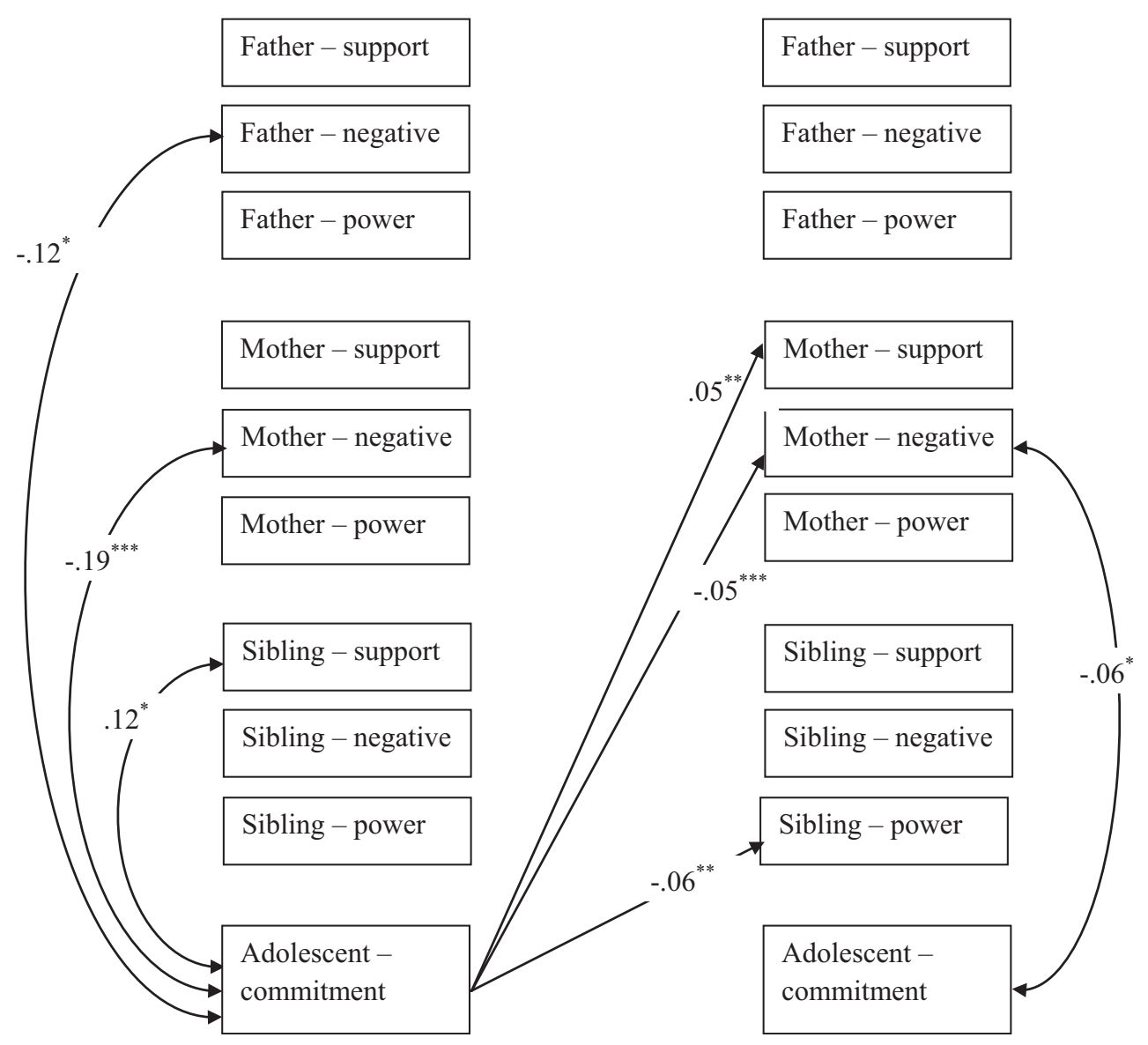

Figure 2. Significant standardized results of the cross-lagged model linking family relationships to commitment. For the sake of clarity, stability paths and correlations among family dimensions are not reported. Because the model with time-invariant coefficients was retained as the final one, we present only two time points $(T$ and $T+1)$, and all coefficients displayed represent the averaged standardized coefficients over the five time intervals. Negative $=$ negative interaction.

$* p<.05 . * *<.01 .{ }^{* * *} p<.001$. 
$\mathrm{T} 1$

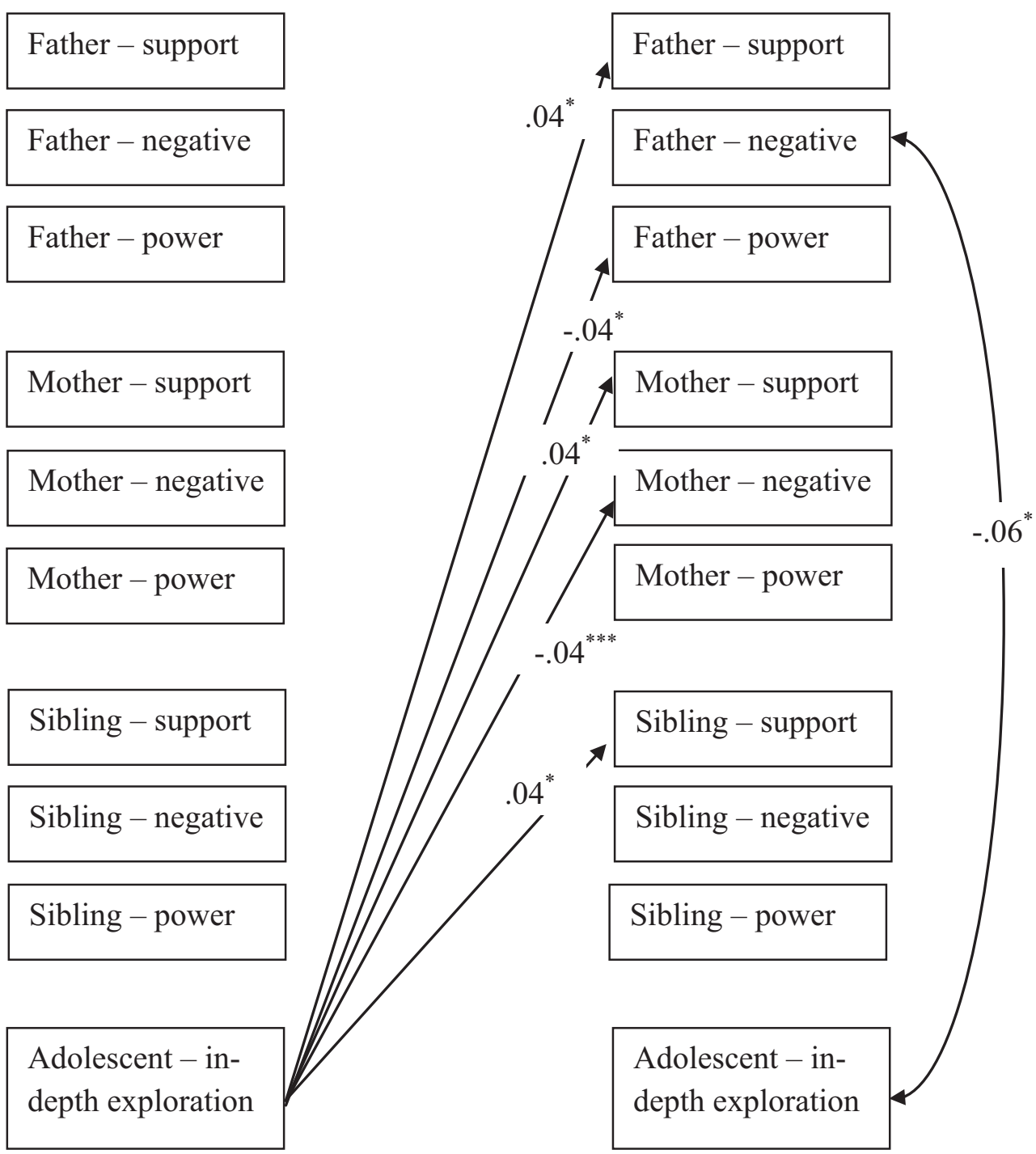

Figure 3. Significant standardized results of the cross-lagged model linking family relationships to in-depth exploration. For the sake of clarity, stability paths and correlations among family dimensions are not reported. Because the model with time-invariant coefficients was retained as the final one, we present only two time points $(T$ and $T+1)$, and all coefficients displayed represent the averaged standardized coefficients over the five time intervals. Negative $=$ negative interaction. $* p<.05 . * * * p<.001$.

fathers more equal, and lessening negative interactions with mothers. Moreover, at T2-T5, in-depth exploration was negatively related to paternal negative interaction.

\section{Family Relationships and Identity Reconsideration of Commitment}

As shown in Figure 4, cross-lagged effects found in the model relating family dimensions and identity reconsideration of commitment indicated bidirectional linkages. Specifically, maternal support negatively predicted later reconsideration of commitment, while reconsideration of commitment lessened later paternal support. In addition, at T1, reconsideration of commitment was negatively related to paternal, maternal, and sibling support. Moreover, at $\mathrm{T} 2-\mathrm{T} 5$, reconsideration of commitment was positively related to paternal and maternal negative interaction, and to maternal power. 
$\mathrm{T} 1$

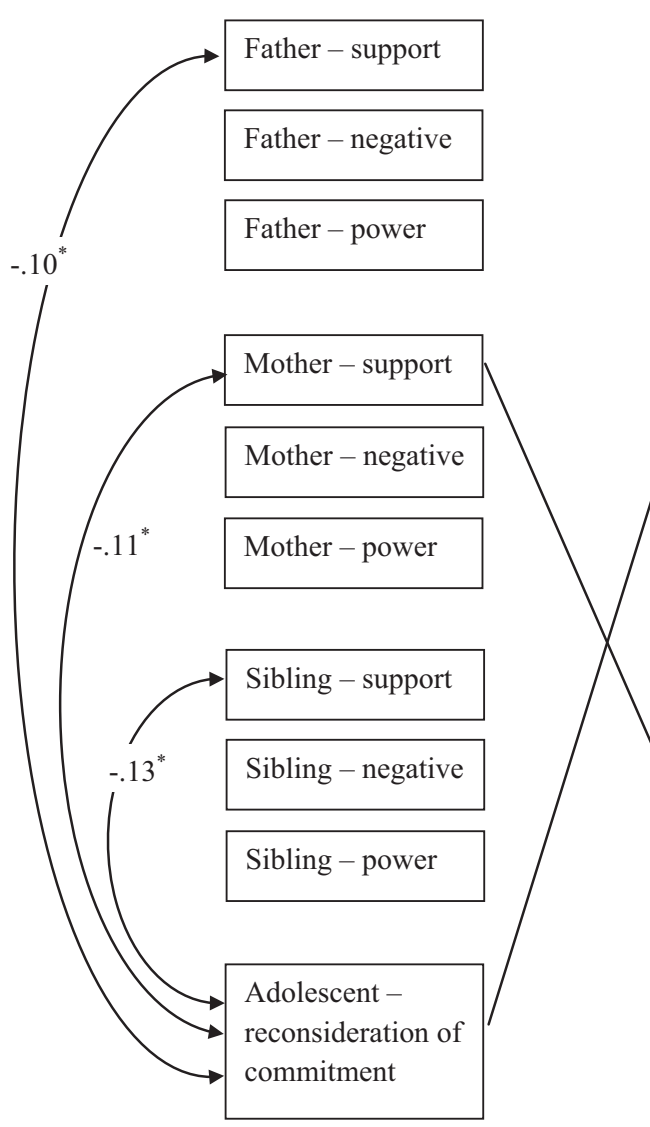

$\mathrm{T} 1+1$

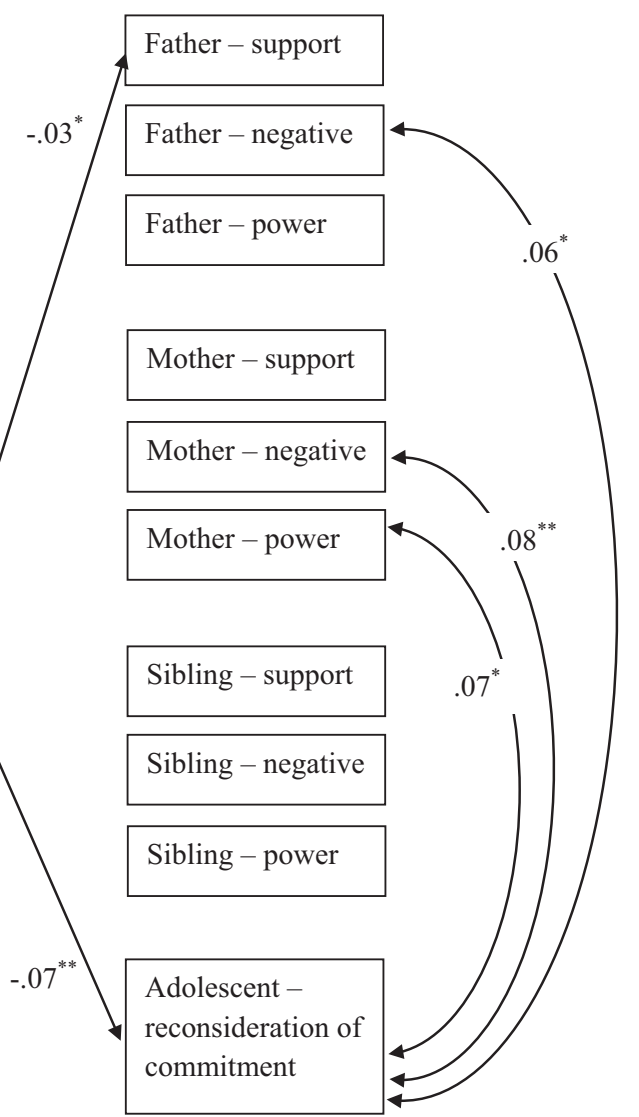

Figure 4. Significant standardized results of the cross-lagged model linking family relationships to reconsideration of commitment. For the sake of clarity, stability paths and correlations among family dimensions are not reported. Because the model with time-invariant coefficients was retained as the final one, we present only two time points $(T$ and $T+1)$, and all coefficients displayed represent the averaged standardized coefficients over the five time intervals. Negative $=$ negative interaction.

$* p<.05, * * p<.01$.

\section{Discussion}

Achievement of a stable sense of identity is a core challenge for adolescents. Especially in contemporary societies, where clear and shared societal guidelines are often missing and adolescents can find identity alternatives somewhat overwhelming (e.g., Schwartz, 2000), the interaction with significant others can make the difference in the identity formation process. The first system with which adolescents regularly interact is represented by their family (e.g., Scabini \& Manzi, 2011), in which both intergenerational (with parents) and intragenerational (with siblings) exchanges can foster adolescents' identity pathways.

In this study, we sought to provide a novel contribution to the literature on family and identity. We unfolded the mutual associations between family relationships and identity, testing the bidirectional hypothesis that not only family relationships affect identity, but also adolescent identity can impact the quality of family relationships. We addressed this goal in a fully recursive five-wave longitudinal study in which 14 years old adolescents were followed until they were 18 years old. The entire family participated in the study; thus, fathers, mothers, and siblings rated directly their relationships with the target adolescents along multiple dimensions of support, negative interaction, and power (Furman \& Buhrmester, 1985).

Results highlighted an interesting pattern of associations consistent over the course of adolescence that improve our understanding of the interplay of family relationships and identity formation. First, results of within-time correlations indicated that identity certainty was related to nurturing family relationships (Bowlby, 1988; Grotevant \& Cooper, 1985; Grotevant \& Cooper, 1986). Indeed, at the beginning of the study (T1), commitment 
Table 4

One-Year and Two-Year Standardized Stability Paths for Family Dimensions and Identity

\begin{tabular}{llr}
\hline & 1 year (range) & 2 year (range) \\
\hline Fathers & & \\
$\quad$ Support & $.46^{* * *}-.67^{* * *}$ & $.24^{* * *}-.35^{* * *}$ \\
Negative interaction & $.50^{* * *}-.67^{* * *}$ & $.15^{*}-.27^{* * *}$ \\
$\quad$ Power & $.43^{* * *}-.60^{* * *}$ & $.35^{* * *}-.38^{* * *}$ \\
Mothers & & \\
Support & $.47^{* * *}-66^{* * *}$ & $.29^{* * *}-.34^{* * *}$ \\
Negative interaction & $.45^{* * *}-.63^{* * *}$ & $.25^{* * *}-.32^{* * *}$ \\
Power & $.37^{* * *}-.64^{* * *}$ & $.36^{* * *}-.47^{* * *}$ \\
Siblings & & \\
Support & $.54^{* * *}-.67^{* * *}$ & $.19^{* * *}-.24^{* * *}$ \\
Negative interaction & $.52^{* * *}-.64^{* * *}$ & $.15^{*}-.24^{* * *}$ \\
Power & $.41^{* * *}-.68^{* * *}$ & $.27^{* * *}-.32^{* * *}$ \\
Adolescents' identity & & $.18^{* * *}-.34^{* * *}$ \\
Commitment & $.30^{* * *}-.49^{* * *}$ & $.11-.33^{* * *}$ \\
In-depth exploration & $.31^{* * *}-.52^{* * *}$ & $.06-.21^{* * *}$ \\
Reconsideration & $.31^{* * *}-.42^{* * *}$ & \\
$\quad$ & & \\
\hline
\end{tabular}

$* p<.05 . * * * p .001$.

was negatively related to paternal and maternal negative interaction and positively related to sibling support, whereas reconsideration of commitment was negatively related to paternal, maternal, and sibling support. Furthermore, over the course of the study (T2-T5), commitment and in-depth exploration were negatively related to maternal and paternal negative interaction, respectively; reconsideration was positively associated with maternal and paternal negative interaction, and maternal power. Second, cross-lagged effects pointed out that not only family relationships affected identity, but also identity had significant effects on family relationships, as we will further discuss below. Importantly, associations between family relationships and identity were not moderated by adolescent gender, sibling gender similarity, and sibling age, suggesting that results applied equally to gender subgroups and were not affected by sibling characteristics.

\section{Effects of Parent-Child Relationships on Adolescents' Identity}

Various theoretical models have posited the emphasis on how parents can affect adolescents' identity. In this regard, it has been questioned whether adolescents' identity is triggered by parents' separation (Blos, 1979) or by parents' connectedness and closeness (Bowlby, 1988). Our findings further add to this theoretical debate and, consistent with a growing corpus of evidence (Årseth et al., 2009; Meeus, 2011; Meeus et al., 2005), point out that identity is promoted by warm and supportive parent-child relationships. In fact, we found that mothers' levels of support negatively predicted relative changes in adolescents' reconsideration of commitment over the course of adolescence. In other words, when adolescents received less support from their mothers they question more their identity becoming more uncertain about their current commitments. These findings, taken together with those showing the adolescents enter adolescence already with moderate to high levels of commitment (Klimstra, Hale, Raaijmakers, Branje, \& Meeus, 2010), are consistent with the view that youth do not start the

Table 5

Correlations Among Family Dimensions at T1 (Above the Diagonal) and T2-T5 (Below the Diagonal)

\begin{tabular}{|c|c|c|c|c|c|c|c|c|c|}
\hline & 1 & 2 & 3 & 4 & 5 & 6 & 7 & 8 & 9 \\
\hline \multicolumn{10}{|l|}{ Fathers } \\
\hline 1. Support & - & $-.28^{* * *}$ & .11 & $.21^{* * *}$ & $-.15^{* *}$ & $-.09^{*}$ & $.23^{* * *}$ & -.09 & -.09 \\
\hline 2. Negative interaction & $-.18^{* * *}$ & - & $.24^{* * *}$ & $-.10^{*}$ & $.41^{* * *}$ & $.16^{* * *}$ & $-.17^{* * *}$ & $.22^{* * *}$ & $.14^{*}$ \\
\hline 3. Power & $.08^{* *}$ & $.15^{* * *}$ & - & .04 & .01 & $.12^{*}$ & $.11^{*}$ & -.06 & .01 \\
\hline \multicolumn{10}{|l|}{ Mothers } \\
\hline 4. Support & $.13^{* * *}$ & $-.15^{* * *}$ & .01 & - & $-.13^{* *}$ & .03 & $.10^{*}$ & -.02 & .01 \\
\hline 5. Negative interaction & $-.09^{* *}$ & $.33^{* * *}$ & -.00 & $-.22^{* * *}$ & - & $.30^{* * *}$ & $-.14^{* *}$ & $.20^{* * *}$ & $.15^{*}$ \\
\hline 6. Power & -.02 & $.12^{* * *}$ & .04 & -.01 & $.29^{* * *}$ & - & .01 & .02 & .03 \\
\hline \multicolumn{10}{|l|}{ Siblings } \\
\hline 7. Support & .04 & -.05 & .03 & $.08^{* *}$ & $-.07^{* *}$ & -.02 & - & $-.44^{* * *}$ & .10 \\
\hline 8. Negative interaction & -.05 & $.13^{* * *}$ & -.02 & -.03 & $.15^{* * *}$ & .05 & $-.27^{* * *}$ & - & $.26^{* * *}$ \\
\hline 9. Power & .02 & .04 & -.01 & -.00 & $.07^{*}$ & .04 & $.08^{*}$ & $.16^{* * *}$ & - \\
\hline
\end{tabular}

${ }^{*} p<.05 .{ }^{* *} p<.01 .{ }^{* * *} p<.001$. 
identity development process with a "blank slate" (Meeus et al., 2010, p. 1567), rather they move from their earlier identifications. These childhood identifications are often based on examples and models provided by parents (Erikson, 1950), so when parents (especially mothers) become less supportive adolescents are likely to start doubting about these choices and searching for new alternatives. Thus, these findings point to the importance of support in parent-adolescent relationships (Branje et al., 2002; Lanz \& Tagliabue, 2014).

Our results further point to the problematic character of reconsideration of commitment. High levels of reconsideration of commitment express a condition of identity uncertainty and lead to the negative side depicted in Erikson's (1968) continuum, which is identity confusion. Importantly, reconsideration of commitment is associated with a cluster of problems, including low emotional stability and selfconcept clarity (Morsunbul et al., 2014), high internalizing (anxiety and depression) and externalizing (aggression and delinquency) problem behaviors (Crocetti et al., 2013; Crocetti, Klimstra, et al., 2009; Klimstra et al., 2011), and low well-being (Karaś, Cieciuch, Negru, \& Crocetti, 2015). Therefore, reconsideration of commitment is strongly intertwined with disequilibrium and distress, assuming the character of an identity crisis. In relation to this point, findings of this study have important practical implications. In fact, they suggest that supportive mothers can reduce adolescents' reconsideration of commitment. Therefore, parenting training programs promoting supportive family relationships can elicit a relational context that facilitates adolescent identity formation.

\section{Effects of Adolescents' Identity on Family Relationships}

While most literature on family relationships and identity has predominantly looked at parents' effects, drawing from Erikson's (1950) psychosocial theory, we could expect that also adolescents' identity can have an impact on the quality of family relationships. In this study, we found strong support for this hypothesis. In fact, results indicated that most significant cross-lagged paths were actually from adolescents' identity to quality of family relationships. Importantly, identity predicted changes in relationships with both parents and siblings.

Specifically, we found that adolescents' commitment had a positive effect on the relationships with both the mother and the sibling, making the relationship with the mother more supportive and less conflictual and the relationship with the sibling more egalitarian. Adolescents' in-depth exploration improved the relationship with all family members, leading to a more supportive and equal relationship with the father, a more supportive and less conflictual relationship with the mother, and a more supportive relationship with the sibling. Finally, adolescents' reconsideration of commitment worsened parent-child relationships, decreasing paternal support.

These findings suggest that when adolescents are involved in consolidating their sense of identity (commitment and in-depth exploration are at the basis of the identity-maintenance cycle that leads to a sense of identity synthesis; Meeus, 2011; Meeus et al., 2010), they also improve their relationships with their parents and siblings. These results are consistent with findings of Beyers and Goossens' (2008) study with college students, in which the authors also found that processes involved in the identity-maintenance cycle predicted increases in supportive parenting by fathers and mothers. Overall, this set of evidence underscores that this positive effect of the identity-maintenance cycle is already playing a role in middle to late adolescence and continues to be similarly effective in emerging adulthood. In contrast, when adolescents are engaged in questioning and revising their identity, they worsen their relationships with their parents. This is consistent with results reported by Schwartz et al. (2009), who found that in adolescence family functioning was negatively related to Eriksonian indicators of identity confusion.

It has been suggested that associations between parent-child relationships and identity could be different for fathers and mothers (Beyers \& Goossens, 2008). However, prior findings obtained from college students did not yield univocal results (Benson et al., 1992; Fullinwider-Bush \& Jacobvitz, 1993; Samuolis et al., 2001). In our study, we found that the overarching pattern of results for mothers and fathers was rather similar, although some differences emerged. In particular, we found that higher levels of commitment led to a relative increase in maternal support, while higher levels of reconsideration of commitment led to a relative decrease in paternal support. These results could suggest that mothers are more responsive to signs of identity certainty displayed by their children, whereas fathers are more reactive to signs of identity uncertainty. Future studies are needed to further clarify these differential associations.

Importantly, in this study we shed new light on the associations between adolescent identity and 
sibling relationships. We expected to find bidirectional associations, with a positive relationship with siblings fostering identity formation, and identity maturity leading to improvements in sibling relationships. However, our findings provided support for the effects of identity on sibling relationships, but did not confirm the hypothesized paths from sibling relationships to identity. This unidirectional effect might be explained by the fact that the influence of siblings on psychosocial development tend to become weaker in adolescence than it was in childhood (Buist et al., 2013). Furthermore, we found that the associations between family relationships and identity did not vary according to sibling gender similarity and sibling birth of order. This might relate to the fact that sibling relationships tend to become more egalitarian over the course of adolescence (Buhrmester \& Furman, 1990). Thus, status differences between younger and older siblings that characterize childhood disappear in adolescence.

Overall, findings of our study are consistent with Erikson's (1968) and Adams and Marshall's (1996) conceptualizations, according to which identity development can be conceived as a process of person-context transactions. In this view, identity can be seen as a "social-psychological construct that reflects social influences through imitation and identification processes and active self-construction in the creation of what is important to the self and to others" (Adams \& Marshall, 1996, p. 433). This points to the importance of studying the person in context (Beyers \& Çok, 2008; Bosma \& Kunnen, 2008) to comprehensively understand identity formation, as identity is actively constructed in a relational context and affects the context itself.

The mechanisms through which adolescents' identity foster this improvement in family relationships can be further understood referring to Erikson's (1968) notion that identity fulfills a selfregulatory function (Adams \& Marshall, 1996). This self-regulatory capacity provided by identity security can pose the basis for intimacy and generativity, aspects that Erikson (1950) theorized as consequences of identity development (Beyers \& Seiffge-Krenke, 2010). In adolescence, these effects can already be visible in the improvement of the quality of family relationships, revealing that adolescents with a more stable identity are prone to relate in a closer and equal way with their parents and siblings. Furthermore, this improvement in the quality of family relationships can be further understood considering that identity security goes together with a constellation of positive outcomes (e.g., lower internalizing and externalizing problem behaviors, higher self-esteem, and well-being; Karaś et al., 2015) that can improve the ways in which young people interact with others.

In this respect, this improvement in family relationships prompted by adolescents' identity can be understood as the way in which parents and siblings respond to the maturation processes of adolescents. In fact, when parents and siblings see the adolescents' committed, active in thoughtful exploring their choices, and certain about themselves, they are likely to appreciate their maturation. This approval can be expressed in increasing levels of support, less conflicts, and a more equal relationship. Thus, findings of our study are consistent with the relationship erosion effect, according to which adolescents' problems lead to deterioration in relationship quality. This predominant child effect has been found in longitudinal studies, for instance, for adolescent internalizing (Branje, Hale, Frijns, \& Meeus, 2010) and externalizing (Keijsers, Branje, VanderValk, \& Meeus, 2010) problems. In this study, we detected that the identity pattern inversely related to these problems (a pattern of identity certainty characterized by increasing commitment and in-depth exploration, and decreasing reconsideration of commitment; Crocetti et al., 2013; Crocetti, Klimstra, et al., 2009) leads to an improvement in the relationship quality, further supporting the view that family behaviors are interactively elicited by adolescents' characteristics instead of being unilaterally explained by parenting practices (Kerr, Stattin, Biesecker, \& Ferrer-Wreder, 2003).

\section{Strengths and Limitations of This Study and Suggestions for Future Research}

This study provided new insights into our understanding of the interplay of family relationships and identity. It should be considered both in light of its strengths and shortcomings, which suggest future lines of research. A first strength of this study was its fully recursive and multi-informant longitudinal design involving all family members. Thus, as widely advocated (Luyckx et al., 2007), we did not rely on adolescents' self-reports of family relationships, rather we related adolescents' identity processes to evaluations of family relationships provided directly by fathers, mothers, and siblings. This could account for the small effects detected in this study (see also Adachi \& Willoughby, 2015, for a discussion on the meaningfulness of small effect 
sizes in cross-lagged models). Future studies could further extend current evidence in two directions. First, they should investigate whether adolescent identity is related similarly to adolescents' perceptions of their family relationships as it is to mothers', fathers', and siblings' perceptions. Second, they should consider at the same time adolescents', mothers', fathers', and siblings' perceptions, allowing to examine how adolescent identity is related to the interdependence of these perceptions (Kenny et al., 2006; Scabini et al., 2006). For instance, it would be interesting to study whether enactment of a more mature identity would promote more convergent perspectives, with adolescents' perception of mothers' support being more strongly related to mothers' report of their own support. This would suggest that when adolescents become more certain about themselves they are also better able to capture others' perspectives of the relationship quality. Furthermore, examining perceptions of all family members would provide new insights for understanding how identity is reflected in feedbacks from the social environment, consistent with the view that the self-image is mirrored in, as indicated by Cooley's (1908) concept of "looking-glass self," and confirmed by others (Adams \& Marshall, 1996; Erikson, 1968).

An additional strength of this study was the test of different theories that could explain how family relationships and identity are intertwined. Considering different indicators of relationship quality, we could examine whether adolescent identity was more related to nurturing or to conflicting family relationships. In contrast, we could not test the individuation model of family relationships (Grotevant \& Cooper, 1985; Grotevant \& Cooper, 1986), which emphasizes that adolescent identity should be promoted by a combination of high connectedness with parents and support of individuality. Thus, future longitudinal studies are needed to further unveil how this specific combination of connectedness and support of individuality can enhance adolescent identity certainty.

A further strength of this study was the inclusion of siblings in the analysis of how family relationships are intertwined with adolescents' identity. We found unidirectional effects, with adolescents' identity predicting changes in the relationship with siblings, whereas the quality of the sibling relationships did not affect identity. Although this is an important step in understanding how close relationships within the family and adolescents' identity influence each other, future studies are needed to further uncover this issue, clarifying the role of nonfamily members. In adolescence, in fact, youth can find other important "identity agents" (Schachter \& Marshall, 2010) also in intergenerational relationships with nonfamily adults (e.g., teachers) and intragenerational relationships with friends (Sugimura \& Shimizu, 2010). Future longitudinal studies are highly required to disentangle the dynamic process underpinning adolescent identity formation and transactions with meaningful members of adolescents' social network.

Finally, our study involved Dutch families with medium or high socioeconomic status. Thus, we do not know if our findings would be replicated in other family types and in other cultural groups. An important direction for future research could be to uncover the interplay of family relationships and identity focusing on different types of families (e.g., multiproblematic families, adoptive families), and across various cultural contexts. For instance, prior cross-sectional research established that reconsideration of commitment is more tied to problematic family relationships in cultural contexts in which adolescents are expected to make a transition to adulthood earlier than in contexts, such as Mediterranean countries, in which this transition is strongly postponed (Crocetti, Schwartz, Fermani, Klimstra, \& Meeus, 2012). In these latter contexts, parents can consider adolescents' considering and reconsidering identity choices more acceptable, since the time in which their children would enact enduring adult choices is postponed until the late 20s/early 30s (Crocetti, Rabaglietti, \& Sica, 2012). Therefore, future longitudinal studies might unravel if associations between family and identity processes are similar or differ across cultural contexts.

\section{Conclusions}

In this longitudinal study, we found unidirectional effects of adolescents' identity commitment and in-depth exploration on family relationships and reciprocal associations between family relationships and adolescents' reconsideration of commitment. Results highlighted that when adolescents receive less support from their mothers they start to question their identity, reconsidering their current commitments. Additionally, when adolescents show identity progressions, expressed by increasing levels of commitment, in-depth exploration, and decreasing levels of reconsideration of commitment, they improve their relationships both with their fathers and mothers and also with their siblings. 


\section{References}

Adachi, P., \& Willoughby, T. (2015). Interpreting effect sizes when controlling for stability effects in longitudinal autoregressive models: Implications for psychological science. European Journal of Developmental Psychology, 12, 116-128. doi:10.1080/17405629.2014.963549

Adams, G. R., \& Marshall, S. (1996). A developmental social psychology of identity: Understanding the person in context. Journal of Adolescence, 19, 1-14. doi:10.1006/ jado.1996.0041

Årseth, A. K., Kroger, J., Martinussen, M., \& Marcia, J. E. (2009). Meta-analytic studies of identity status and the relational issues of attachment and intimacy. Identity, 9, 1-32. doi:10.1080/15283480802579532

Bandura, A. (1977). Social learning theory. Englewood Cliffs, NJ: Prentice Hall.

Benson, M. J., Harris, P. B., \& Rogers, C. S. (1992). Identity consequences of attachment to mothers and fathers among late adolescents. Journal of Research on Adolescence, 2, 187-204. doi:10.1207/s15327795jra0203_1

Beyers, W., \& Çok, F. (2008). Adolescent self and identity development in context. Journal of Adolescence, 31, 147150. doi:10.1016/j.adolescence.2008.03.002

Beyers, W., \& Goossens, L. (2008). Dynamics of perceived parenting and identity formation in late adolescence. Journal of Adolescence, 31, 165-184. doi:10.1016/j.adolescence.2007.04.003

Beyers, W., \& Seiffge-Krenke, I. (2010). Does identity precede intimacy? Testing Erikson's theory on romantic development in emerging adults of the 21st century. Journal of Adolescent Research, 25, 387-415. doi:10.1177/ 0743558410361370

Blos, P. (1979). The adolescent passage: Developmental issues. New York, NY: International Universities Press.

Bosma, H. A., \& Kunnen, E. S. (2008). Identity-in-context is not yet identity development-in-context. Journal of Adolescence, 31, 281-289. doi:10.1016/j.adolescence.2008.03.001

Bowlby, J. (1988). A secure base: Parent-child attachment and healthy human development. New York, NY: Basic Books.

Branje, S. J. T., Hale, W. W., Frijns, T., \& Meeus, W. H. J. (2010). Longitudinal associations between perceived parent-child relationship quality and depressive symptoms in adolescence. Journal of Abnormal Child Psychology, 38, 751-763. doi:10.1007/s10802-010-9401-6

Branje, S. J. T., Van Aken, M. A. G., \& Van Lieshout, C. F. M. (2002). Relational support in families with adolescents. Journal of Family Psychology, 16, 351-362. doi:10.1037/ / 0893-3200.16.3.351

Branje, S. J. T., Van Lieshout, C. F. M., Van Aken, M. A. G., \& Haselager, G. J. T. (2004). Perceived support in sibling relationships and adolescent adjustment. Journal of Child Psychology and Psychiatry and Allied Disciplines, 45, 1385-1396. doi:10.1111/j.1469-7610.2004.00332.x

Brody, G. H. (1998). Sibling relationship quality: Its causes and consequences. Annual Review of Psychology, $49,1-24$.
Bronfenbrenner, U. (1979). The ecology of human development: Experiments by nature and design. Cambridge, Massachusetts, MA: Harvard University Press.

Buhrmester, D., \& Furman, W. (1990). Perceptions of sibling relationships during middle childhood and adolescence. Child Development, 61, 1387-1398.

Buist, K. L., Deković, M., Meeus, W., \& Van Aken, M. A. G. (2002). Developmental patterns in adolescent attachment to mother, father and sibling. Journal of Youth and Adolescence, 31, 167-176. doi:10.1023/A:1015074701280

Buist, K. L., Deković, M., \& Prinzie, P. (2013). Sibling relationship quality and psychopathology of children and adolescents: A meta-analysis. Clinical Psychology Review, 33, 97-106. doi:10.1016/j.cpr.2012.10.007

Byrne, B. M. (2012). Structural equation modeling with Mplus: Basic concepts, applications, and programming (2nd ed.). New York, NY: Routledge, Taylor \& Francis Group.

Chen, F. F. (2007). Sensitivity of goodness of fit indexes to lack of measurement invariance. Structural Equation Modeling, 14, 464-504.

Cooley, C. H. (1908). Human nature and the social order. New York, NY: Scribner.

Crocetti, E., Cieciuch, J., Gao, C. H., Klimstra, T., Lin, C. L., Matos, P. M., . . . Meeus, W. (2015). National and gender measurement invariance of the Utrecht-Management of Identity Commitments Scale (U-MICS): A tennation study. Assessment, 22, 753-768. doi:10.1177/ 1073191115584969

Crocetti, E., Klimstra, T. A., Hale, W. W., Koot, H. M., \& Meeus, W. (2013). Impact of early adolescent externalizing problem behaviors on identity development in middle to late adolescence: A prospective 7-year longitudinal study. Journal of Youth and Adolescence, 42, 1745-1758. doi:10.1007/s10964-013-9924-6

Crocetti, E., Klimstra, T., Keijsers, L., Hale, W. W., \& Meeus, W. (2009). Anxiety trajectories and identity development in adolescence: A five-wave longitudinal study. Journal of Youth and Adolescence, 38, 839-849. doi:10.1007/s10964-008-9302-y

Crocetti, E., \& Meeus, W. (2014). "Family comes first!" Relationships with family and friends in Italian emerging adults. Journal of Adolescence, 37, 1463-1473. doi:10.1016/j.adolescence.2014.02.012

Crocetti, E., Rabaglietti, E., \& Sica, L. S. (2012). Personal identity in Italy. New Directions for Child and Adolescent Development, 138, 87-102. doi:10.1002/cad.20023

Crocetti, E., Rubini, M., Berzonsky, M. D., \& Meeus, W. (2009). Brief report: The Identity Style Inventory: Validation in Italian adolescents and college students. Journal of Adolescence, 32, 425-433. doi:10.1016/ j.adolescence.2008.04.002

Crocetti, E., Rubini, M., \& Meeus, W. (2008). Capturing the dynamics of identity formation in various ethnic groups: Development and validation of a three-dimensional model. Journal of Adolescence, 31, 207-222. doi:10.1016/j.adolescence.2007.09.002

Crocetti, E., Schwartz, S. J., Fermani, A., Klimstra, T., \& Meeus, W. (2012). A cross-national study of identity 
status in Dutch and Italian adolescents status distributions and correlates. European Psychologist, 17, 171-181. doi:10.1027/1016-9040/a000076

Crocetti, E., Schwartz, S. J., Fermani, A., \& Meeus, W. (2010). The Utrecht-Management of Identity Commitments Scale (U-MICS): Italian validation and crossnational comparisons. European Journal of Psychological Assessment, 26, 172-186. doi:10.1027/1015-5759/a000024

De Goede, I. H. A., Branje, S. J. T., \& Meeus, W. H. J. (2009). Developmental changes in adolescents' perceptions of relationships with their parents. Journal of Youth and Adolescence, 38, 75-88. doi:10.1007/s10964-008-9286-7

Defoe, I. N., Keijsers, L., Hawk, S. T., Branje, S., Dubas, J. S., Buist, K., \& Meeus, W. (2013). Siblings versus parents and friends: Longitudinal linkages to adolescent externalizing problems. Journal of Child Psychology and Psychiatry and Allied Disciplines, 54, 881-889. doi:10.1111/jcpp.12049

Erikson, E. (1950). Childhood and society. New York, NY: Norton.

Erikson, E. H. (1968). Identity, youth and crisis. New York, NY: Norton.

Fullinwider-Bush, N., \& Jacobvitz, D. B. (1993). The transition to young adulthood: Generational boundary dissolution and female identity development. Family Process, 32, 87-103.

Furman, W., \& Buhrmester, D. (1985). Children's perceptions of the personal relationships in their social networks. Developmental Psychology, 21, 1016-1024. doi:10.1037/0012-1649.21.6.1016

Furman, W., \& Buhrmester, D. (1992). Age and sex differences in perceptions of networks of personal relationships. Child Development, 63, 103-115.

Grotevant, H. D., \& Cooper, C. R. (1985). Patterns of interaction in family relationships and the development of identity exploration in adolescence. Child Development, 56, 415-428.

Grotevant, H. D., \& Cooper, C. R. (1986). Individuation in family relationships: A perspective on individual differences in the development of identity and role-taking skills in adolescence. Human Development, 29, 82-100.

Karaś, D., Cieciuch, J., Negru, O., \& Crocetti, E. (2015). Relationships between identity and well-being in Italian, Polish, and Romanian emerging adults. Social Indicators Research, 121, 727-743. doi:10.1007/s11205-014-0668-9

Keijsers, L., Branje, S. J. T., VanderValk, I. E., \& Meeus, W. (2010). Reciprocal effects between parental solicitation, parental control, adolescent disclosure, and adolescent delinquency. Journal of Research on Adolescence, 20, 88-113. doi:10.1111/j.1532-7795.2009.00631.x

Kenny, D. A., Kashy, D. A., \& Cook, W. L. (2006). Dyadic data analysis. New York, NY: Guilford.

Kerr, M., Stattin, H., Biesecker, G., \& Ferrer-Wreder, L. (2003). Relationships with parents and peers in adolescence. In R. M. Lerner, M. A. Easterbrooks, \& J. Mistry (Eds.), Handbook of psychology: Vol. 6. Developmental psychology (pp. 395-419). Hoboken, NJ: Wiley.
Klimstra, T. A., Crocetti, E., Hale, W. W., Kolman, A. I. M., Fortanier, E., \& Meeus, W. H. J. (2011). Identity formation in juvenile delinquents and clinically referred youth. European Review of Applied Psychology, 61, 123-130. doi:10.1016/j.erap.2011.05.002

Klimstra, T. A., Hale, W. W., Raaijmakers, Q. A. W., Branje, S. J. T., \& Meeus, W. H. J. (2010). Identity formation in adolescence: Change or stability? Journal of Youth and Adolescence, 39, 150-162. doi:10.1007/s10964-009-9401-4

Kroger, J., \& Haslett, S. J. (1988). Separation-individuation and ego identity status in late adolescence: A two-year longitudinal study. Journal of Youth and Adolescence, 17, 59-79. doi:10.1007/BF01538724

Lanz, M., \& Tagliabue, S. (2014). Supportive relationships within ongoing families: Cross-lagged effects between components of support and adjustment in parents and young adult children. Journal of Adolescence, 37, 14891503. doi:10.1016/j.adolescence.2014.07.017

Little, R. J. A. (1988). A test of missing completely at random for multivariate data with missing values. Journal of the American Statistical Association, 83, 11981202.

Luyckx, K., Goossens, L., \& Soenens, B. (2006). A developmental contextual perspective on identity construction in emerging adulthood: Change dynamics in commitment formation and commitment evaluation. Developmental Psychology, 42, 366-380. doi:10.1037/ 0012-1649.42.2.366

Luyckx, K., Soenens, B., \& Goossens, L. (2006). The personality-identity interplay in emerging adult women: Convergent findings from complementary analyses. European Journal of Personality, 20, 195-215. doi:10.1002/ per.579

Luyckx, K., Soenens, B., Vansteenkiste, M., Goossens, L., \& Berzonsky, M. D. (2007). Parental psychological control and dimensions of identity formation in emerging adulthood. Journal of Family Psychology, 21, 546-550. doi:10.1037/0893-3200.21.3.546

Marcia, J. E. (1966). Development and validation of egoidentity status. Journal of Personality and Social Psychology, 3, 551-558. doi:10.1037/h0023281

McHale, S. M., Updegraff, K. A., \& Whiteman, S. D. (2012). Sibling relationships and influences in childhood and adolescence. Journal of Marriage and Family, 74, 913-930. doi:10.1111/j.1741-3737.2012.01011.x

Meeus, W. (2011). The study of adolescent identity formation 2000-2010: A review of longitudinal research. Journal of Research on Adolescence, 21, 75-94. doi:10.1111/ j.1532-7795.2010.00716.x

Meeus, W., Iedema, J., Maassen, G., \& Engels, R. (2005). Separation-individuation revisited: On the interplay of parent-adolescent relations, identity and emotional adjustment in adolescence. Journal of Adolescence, 28, 89-106. doi:10.1016/j.adolescence.2004.07.003

Meeus, W., Oosterwegel, A., \& Vollebergh, W. (2002). Parental and peer attachment and identity development in adolescence. Journal of Adolescence, 25, 93-106. doi:10.1006/jado.2001.0451 
Meeus, W., van de Schoot, R., Keijsers, L., Schwartz, S. J., \& Branje, S. (2010). On the progression and stability of adolescent identity formation: A five-wave longitudinal study in early-to-middle and middle-to-late adolescence. Child Development, 81, 1565-1581. doi:10.1111/ j.1467-8624.2010.01492.x

Morsunbul, U., Crocetti, E., Cok, F., \& Meeus, W. (2014). Brief report: The Utrecht-Management of Identity Commitments Scale (U-MICS): Gender and age measurement invariance and convergent validity of the Turkish version. Journal of Adolescence, 37, 799-805. doi:10.1016/ j.adolescence.2014.05.008

Muthén, L. K., \& Muthén, B. O. (1998-2012). Mplus user's guide (7th ed.). Los Angeles, CA: Author.

Patterson, G. R. (1984). Siblings: Fellow travelers in coercive family processes. Advances in the Study of Aggression, 1, 173-215.

Samuolis, J., Layburn, K., \& Schiaffino, K. M. (2001). Identity development and attachment to parents in college students. Journal of Youth and Adolescence, 30, 373-384. doi:10.1023/A:1010448313516

Satorra, A., \& Bentler, P. M. (2001). A scaled difference chi-square test statistic for moment structure analysis. Psychometrika, 66, 507-514.

Scabini, E., \& Manzi, C. (2011). Family processes and identity. In S. J. Schwartz, K. Luyckx, \& V. L. Vignoles (Eds.), Handbook of identity theory and research (pp. 565-584). New York, NY: Springer.

Scabini, E., Marta, E., \& Lanz, M. (2006). Transition to adulthood and family relations: An intergenerational perspective. London, UK: Taylor \& Francis.

Schachter, E. P., \& Marshall, S. K. (2010). Identity agents: A focus on those purposefully involved in the identity of others. Identity, 10, 71-75. doi:10.1080/1528348100 3711676
Schachter, E. P., \& Ventura, J. J. (2008). Identity agents: Parents as active and reflective participants in their children's identity formation. Journal of Research on Adolescence, 18, 449-476. doi:10.1111/j.1532-7795.2008.00567.x

Schwartz, B. (2000). Self-determination: The tyranny of freedom. American Psychologist, 55, 79-88. doi:10.1037// 0003-066X.55.1.79

Schwartz, S. J., Mason, C. A., Pantin, H., \& Szapocznik, J. (2009). Longitudinal relationships between family functioning and identity development in Hispanic immigrant adolescents: Continuity and change. Journal of Early Adolescence, 29, 177-211. doi:10.1177/0272431608317605

Sugimura, K., \& Shimizu, N. (2010). The role of peers as agents of identity formation in Japanese first-year university students. Identity, 10, 106-121. doi:10.1080/ 15283481003711734

Watzlawik, M., \& Clodius, S. (2011). Interpersonal identity development in different groups of siblings: A longitudinal study. European Psychologist, 16, 43-47. doi:10.1027/1016-9040/a000030

Wong, T. M. L., Branje, S. J. T., VanderValk, I. E., Hawk, S. T., \& Meeus, W. H. J. (2010). The role of siblings in identity development in adolescence and emerging adulthood. Journal of Adolescence, 33, 673-682. doi:10.1016/j.adolescence.2009.11.003

\section{Supporting Information}

Additional supporting information may be found in the online version of this article at the publisher's website:

Appendix S1. Ancillary Analyses

Appendix S2. Multi-Group Analyses: Model Fit Indices and Model Comparisons 